\title{
EDITORIAL
}

\section{The Woodhouse Report 22 years on}

The 1974 Report of the National Committee of Inquiry into Compensation and Rehabilitation in Australia (Woodhouse Inquiry) stated that:

"There is no uniformity between compensation systems throughout Australia. Instead there are ten different systems paying ten differing sets of benefits that reduce or increase not because of loss or need but in terms of geographical boundaries" and that these systems, in terms of assisting people who are injured, are "obsolescent in principle and inadequate in practice."

The Woodhouse Report was particularly critical of the failure of these systems to "grapple in any real way with the rehabilitation of the injured worker". The adversarial nature of claims determination and compensation settlement hindered the provision of reasonable rehabilitation assistance.

In response to these problems Justice Woodhouse recommended the establishment of a national compensation and rehabilitation scheme which would provide rehabilitation and compensation to "every person who at any time or in any place suffers a personal injury". This form of 'universal social insurance' was intended to replace workers compensation schemes and some social security programs, and to provide 24 hour coverage to all people who were injured, regardless of when and where their injuries occurred.

An attempt to introduce a national scheme in 1974 was blocked in the Senate and successive governments have lacked either the political will or philosophical commitment to pursue it further. So where are we at 22 years down the track? Have we implemented other solutions to the problems raised by Justice Woodhouse?

In 1994 the Industry Commission examined workers compensation Australia. Despite substantial reform to workers compensation systems in the 1980's and recent moves by the Heads of Workers Compensation Authorities to introduce consistency between state workers compensation schemes, the Commission noted that Australia still has a multiplicity of Schemes which "do not encourage desirable behaviour on the part of the various parties" in these schemes. It also noted that "rehabilitation and return to work outcomes are still deficient".

Recommendations of the Industry Commission to remedy these problems included the establishment of a national WorkCover Authority to develop a national workers compensation scheme to operate in a parallel with existing schemes. The new authority would also develop national standards and ensure quality of service delivery of insurers and self-insurers involved in the scheme. The commission viewed rehabilitation as most effective when based in the workplace, employers and employees agreed on programs and treatment providers, referral for rehabilitation occurred early, and employers accepted responsibility for maintaining contact and providing support to injured workers.

However, despite the findings and recommendations of Woodhouse and the Industry Commission not much has changed. There is no national scheme, there continues to be a proliferation of compensation schemes in the areas of workers compensation and motor accident insurance and timely access to rehabilitation 
varies considerably between schemes. In some schemes it can be months before injured parties receive rehabilitation, if at all.

As we approach the year 2000 it would seem useful to re-examine the philosophy and far sighted recommendations of the Woodhouse Report. One of problems with the Industry Commission report was that its recommendations were doomed to be a partial solution to the problem of injury as they only dealt with the workers compensation system. This piecemeal approach was heavily criticised by Woodhouse. He viewed injury and illness generally as a social problem, not just an economic problem, for which the community had to accept responsibility. The corollary of community responsibility carried with it the notion of comprehensive entitlement:

Once society as a whole has accepted the need to support those of its members who are burdened by injury and sickness, they could not, in fairness, be... supported by differing levels of compensation, depending merely upon the fortuitous cause of the incapacity... The aim must be an integrated solution for every man and woman and protection throughout the twenty-four hours of every day.

The introduction of a national scheme would require the revamping of the workers compensation, motor accident and social security schemes to provide an integrated consistent approach to dealing with injury and illness. Opponents of such a scheme refer to cost as the major deterrent to a national approach. However both Woodhouse and the Industry Commission provided arguments that a national approach would actually be more cost effective as it eliminated duplication and put an end to the cost shifting from state workers compensation schemes to the federal government.

Justice Woodhouse viewed rehabilitation as central to the compensation system and believed that access to rehabilitation assistance should not be impeded by money disincentives. The Industry Commission was of the view that rehabilitation was of sufficient importance that it should commence as early as possible and, "if necessary, without any acceptance of liability." Access to rehabilitation services for the sick and injured should be universal and not impeded by the medico-legal adversarial basis of some compensation systems.

It is therefore timely that we dust off our copies of the Woodhouse Report. The federal government has an opportunity, within the context of structural reform, to remediate the problems inherent in those insurance systems which compensate injured Australians. The Woodhouse Report offers a vision for change that is consistent with some of the recent moves in Australia towards a national approach that has been adopted on other issues. The rehabilitation community also should be taking a lead to promote such reform. One means to achieve this end would be to advocate for a "compensation summit", bringing together governments, insurers, rehabilitation providers and peak bodies representing the medical community... and perhaps, as a starting point, all delegates should be required to read the Woodhouse Report.

Nicholas Buys

Editor 
